\title{
Detection of the Departure from Nucleate Boiling in Nuclear Fuel Rod Simulators
}

\author{
Amir Zacarias Mesquita and Rogério Rivail Rodrigues \\ Nuclear Technology Development Centre (CDTN), Brazilian Nuclear Energy Commission (CNEN), Campus of UFMG, \\ Pampulha, Belo Horizonte, MG, Brazil
}

Correspondence should be addressed to Amir Zacarias Mesquita; amir@cdtn.br

Received 12 February 2013; Revised 11 May 2013; Accepted 13 May 2013

Academic Editor: Adem Acir

Copyright (C) 2013 A. Z. Mesquita and R. R. Rodrigues. This is an open access article distributed under the Creative Commons Attribution License, which permits unrestricted use, distribution, and reproduction in any medium, provided the original work is properly cited.

\begin{abstract}
In the thermal hydraulic experiments to determin parameters of heat transfer where fuel rod simulators are heated by electric current, the preservation of the simulators is essential when the heat flux goes to the critical point. One of the most important limits in the design of cooling water reactors is the condition in which the heat transfer coefficient by boiling in the core deteriorates itself. The heat flux just before deterioration is denominated critical heat flux (CHF). At this time, the small increase in heat flux or in the refrigerant inlet temperature at the core, or the small decrease in the inlet flux of cooling, results in changes in the heat transfer mechanism. This causes increases in the surface temperature of the fuel elements causing failures at the fuel (burnout). This paper describes the experiments conducted to detect critical heat flux in nuclear fuel element simulators carried out in the thermalhydraulic laboratory of Nuclear Technology Development Centre (CDTN). It is concluded that the use of displacement transducer is the most efficient technique for detecting critical heat flux in nuclear simulators heated by electric current in open pool.
\end{abstract}

\section{Introduction}

One of the most important limits in the design of the watercooled nuclear reactors is the condition in which the heat transfer coefficient for boiling in the core deteriorates. The critical heat flux (CHF) is the heat flux at which a boiling crisis occurs that causes abrupt rise of the fuel rod surface temperature and, subsequently, a failure of the cladding material [1]. Design of a water-cooled reactor requires a sufficient safety margin with regard to the critical heat flux. The importance of CHF in nuclear engineering has led to intensive investigations worldwide over several years.

Experiments show that near the CHF time of occurrence, a small increase of the heat flux or in the inlet temperature of the core coolant or a small decrease in the inlet flux of the coolant results in a change in the heat mechanism transfer, causing an abrupt increase of the temperature in the surface of the fuel rods, causing the cladding burnout. The boiling crisis that causes the critical flux is usually classified into two types as described later.
The drydout that happens when the thickness of the layer of water drops to zero, usually happens in areas of high steam quality and low heat flux.

The departure from nucleate boiling (DNB) happens in the area of low steam quality when there is nucleus formation of bubbles. This results in a departure from nucleate boiling (DNB) in which steam bubbles no longer break away from the solid surface of the channel, bubbles dominate the channel or surface, and the heat flux dramatically decreases. Vapor essentially insulates the bulk liquid from the hot surface.

Figure 1 shows a typical boiling curve for saturated pool boiling of water at atmospheric pressure for a temperaturecontrolled environment (generally called the Nukiyama curve) [2].

One of the rules used in the reactor projects specifies that the heat flux, in continuous operation, should not exceed a determined fraction of the critical flux. This value is specified to maintain the temperature of the fuel elements cladding in safety levels. Therefore, experiments and studies for the development of precise correlation on heat critical flux in 


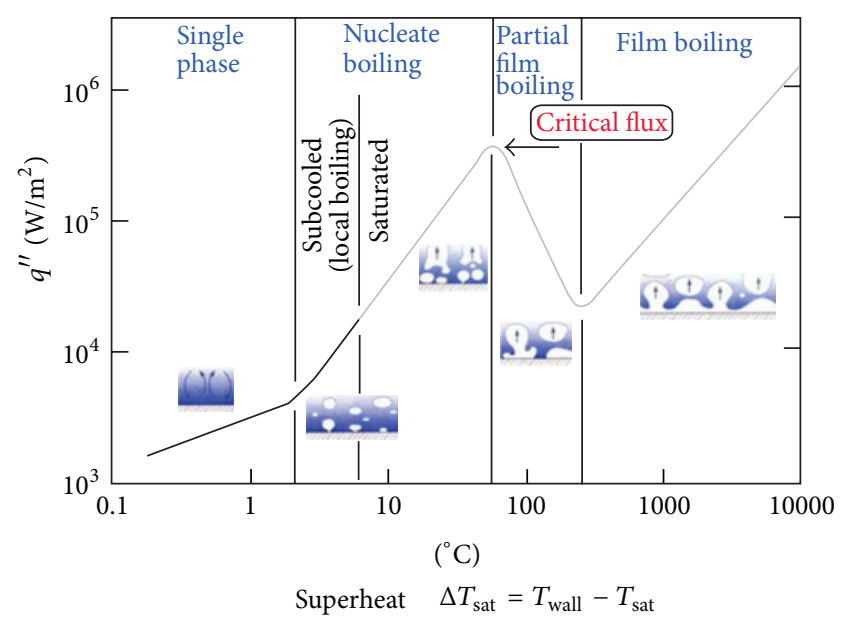

Figure 1: Typical pool boiling curve for water under atmospheric pressure [2].

rod element assemblies give economy and safety in the construction and operation of the nuclear reactors.

Thermal hydraulic experiments are conducted to qualify the model calculations related to the phenomenon that happens in the system, which tries to reproduce at the maximumdexistent conditions in the core. From all these tests, the critical heat flux determination is maybe the most important, because it determines the operation limit of the fuel rods and other components.

\section{Detection of the Critical Heat Flux}

In the thermal hydraulic experiments of heat transfer, where rods electrically heated are used for simulation of the nuclear fuels, the fast shutdown of the power supply is essential to the preservation of the simulators, when the critical heat flux is reached. Mainly in the tests whose purpose is the determination of this parameter, the detection through a fast and safe way facilitates plenty the tests, because the same rod or a set of rods can be used several times.

When the critical flux is reached, there is an abrupt increase of the wall temperature. This temperature increase is used directly for the detection of this phenomenon, or then, indirectly using the effects caused by temperature increase in the physical properties of the tube. Four methods that can be used for the detection will be described below.

2.1. Temperature Measuring. Critical heat flux can be detected by significant change in output of a thermocouple attached to the tube wall near the outlet. Usually, the thermocouple is electrically insulated from the tube using thin mica sheet and thermally insulated from the environment with glass wool. Sometimes, two thermocouples are used and positioned diametrically at the same axial location. Other times, the thermocouple is soldered to a small copper plate which is spring loaded against the tube wall near the outlet [3]. In some tests, several thermocouples are welded along the wall of the tube near the outlet, and they make the monitoring of the temperature. When one abrupt increase of the temperature in some thermocouple happens, the power supply is turned off [4]. This method has several inconveniences:

(i) the speed of the detection depends on the thermocouple proximity of the point where the "burn-out" happens;

(ii) the own thermocouple, depending of its diameter and positioning, can work as a heat sink, contributing to the "burn-out" that happens distantly from it;

(iii) the thermocouple, mainly that of small diameter, is subject to noises originating from the electrical power supply, needing use of filters;

(iv) difficulties in the thermocouples placement in the wall of the tube;

(v) inertia in the thermocouples answer.

2.2. Electric Resistance Measuring. In the place where the burnout happens, there is also an abrupt increase of the electrical resistance. Electric resistance detectors typically consisted of wires attached to the test section at the inlet and outlet electrodes and a wire attached to the tube near the outlet. The electrical resistance of the downstream section (between the two downstream wires) is compared with that of the upstream section in a Wheatstone bridge circuit. On inception of CHF, a sudden rise in wall temperature occurs causing the previously balanced bridge to become unbalanced and, consequently, disengaging the power supply [3].

The departure from nuclear boiling was attained by smooth increase of the heated pipe power at the constant coolant flow rate and was recorded by a special detector operating on the principle of a balanced bridge [5].

This method is quite efficient and independent of the place where the critical flux happens. There are some disadvantages:

(i) it is subject to the noises caused by the magnetic field of the electric current in the rod;

(ii) the sensibility is small when the rod is short (less than $600 \mathrm{~mm}$ );

(iii) when the power supply is turned on, this method is not very practical, with the accomplishment of the unbalance of the bridge.

2.3. Visual Observation. In the place where the CHF happens, can be identified by the appearance of an incandescent spot on the tube wall near the outlet. So the observer is able to turn off the power supply. This detection method is only possible when visual access of the cooling channel is feasible, it is also not very reliable.

2.4. Monitoring of the Linear Expansion. The increase of the temperature causes the dilatation of the rod. It can be shown that when the critical flux occurs, the abrupt increase of the temperature also causes an abrupt dilation [6]. By the use of a sensor displacement coupled in the rod, it is possible to switch off the power supply quickly, avoiding its destruction. This detection method is presented in this paper. 


\section{Materials and Methods}

3.1. Experimental Assembly. To check the efficiency of the dilation detection system a device test was set up as schematically shown at Figure 2. The device consists of an opened tank in stainless steel with external diameter of $60.33 \mathrm{~mm}$, wall of $2.77 \mathrm{~mm}$ and length of $790 \mathrm{~mm}$. The simulator rod is positioned and fixed in the down extremity of the vase and electrically isolated of this.

The rod has its superior extremity free and can expand freely. In this extremity the bobbin core of the displacement transducer is fixed, being the coil fixed in the vase. The transducer used at the experiment and shown at Figure 3 is one of the magnetic types, and its operation will be described in the following item [7].

There were built three fuel rod simulators comprised of stainless steel tubes, with external diameter of $10.75 \mathrm{~mm}$ and internal diameter of $9.75 \mathrm{~mm}$. The lengths were, respectively, $600 \mathrm{~mm}(\operatorname{Rod} 1), 560 \mathrm{~mm}(\operatorname{Rod} 2)$, and $490 \mathrm{~mm}(\operatorname{Rod} 3)$. Along the wall of the rods several thermocouples type $\mathrm{K}$ were soldered, some being with stainless steel shielding of $1.5 \mathrm{~mm}$ and some without shielding (uncoated) with diameter of $0.2 \mathrm{~mm}$. Figure 4 shows the disposition of the thermocouples in the three used rods and the approximate place where rupture of the rod during the tests had existed. The rods just differed in the number and length of thermocouples.

The heating of the rod was made by Joule effect using the own wall of the tube as a resistor. The power supply is a $16 \mathrm{~kW}$ DC rectifier with continuous voltage adjustment. A data acquisition system monitors and records the test conditions and provides automatic power shutdown.

The vase was filled with demineralized water in contact with the atmosphere (open pool). After each test, the water level was completed to compensate the evaporation caused by the heating.

3.2. Displacement Transducer. The displacement sensor consists of a transformer and a core which when moved linearly along the coil axis causes a change in output voltage that is proportional to the movement. It was used a displacement transducer, model 24DCDT-050, manufactured by Hewlett Packard (Figure 3) [7].

The assembly consists of a differential transformer coil, a direct current (DC) excited solid-state oscillator, and phasesensitive demodulator in one package. The oscillator converts the DC input to AC (alternating current) which is used to excite the primary winding. The axial core position determines the amount of voltage induced in the secondary windings. Each of the two secondary circuits contains a secondary winding, a full-wave bridge, and an RC filter. These secondary circuits are connected in series opposition so that the resultant output is a DC voltage proportional to the core displacement from electrical center. The polarity of the voltage is a function of the location of the core with respect to electrical center. The electrical center is the position of the core relative to the coil when the output is zero and is located approximately one half along the coil length. A simplified functional diagram is shown in Figure 5.

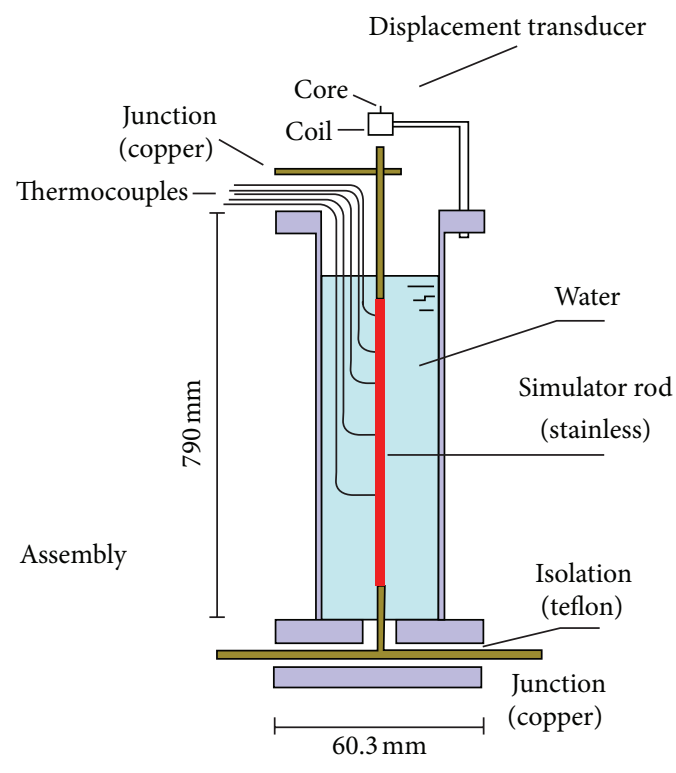

Figure 2: Experimental assembly.

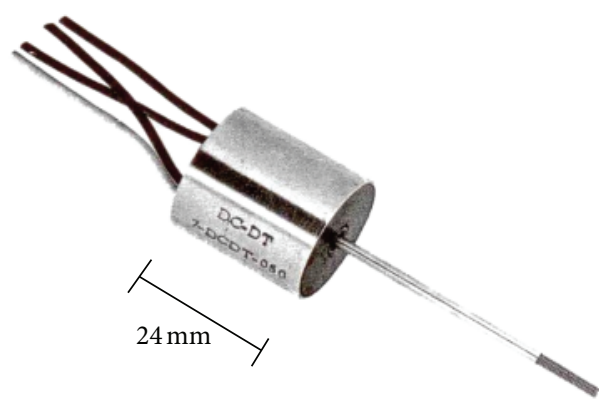

FIgURE 3: Displacement transducer [7].

The input voltage is 24 volt $\mathrm{DC}$, and the ratio of output electric/displacement is $4.17 \mathrm{~V} / \mathrm{mm}$. The resolution capability of the transducer is theoretically infinite but in practice is limited by the measuring instrument connected at the output.

\section{Results and Discussion}

4.1. Heating by Joule Effect. The purpose of the tests was to compare the response of the displacement transducer with the response of the thermocouples at the time of critical flow. For this, the level of power dissipated in the rod simulator in certain value was adjusted and records provided by the thermocouples and displacement transducers were observed. The critical heat flux is characterized by the abrupt increase of the records. As there were no records of the sharp rise, the power level was increased.

When it is too close to the critical flux time, shown by the sudden increase of a recording, the power supply is automatically turned off. In some tests, the power supply was not shut down to cause the occurrence of rupture of the rod intended to observe the behavior of records.

Table 1 shows a sampling of collected data from some tests. The temperature indicated in the table refers to the 


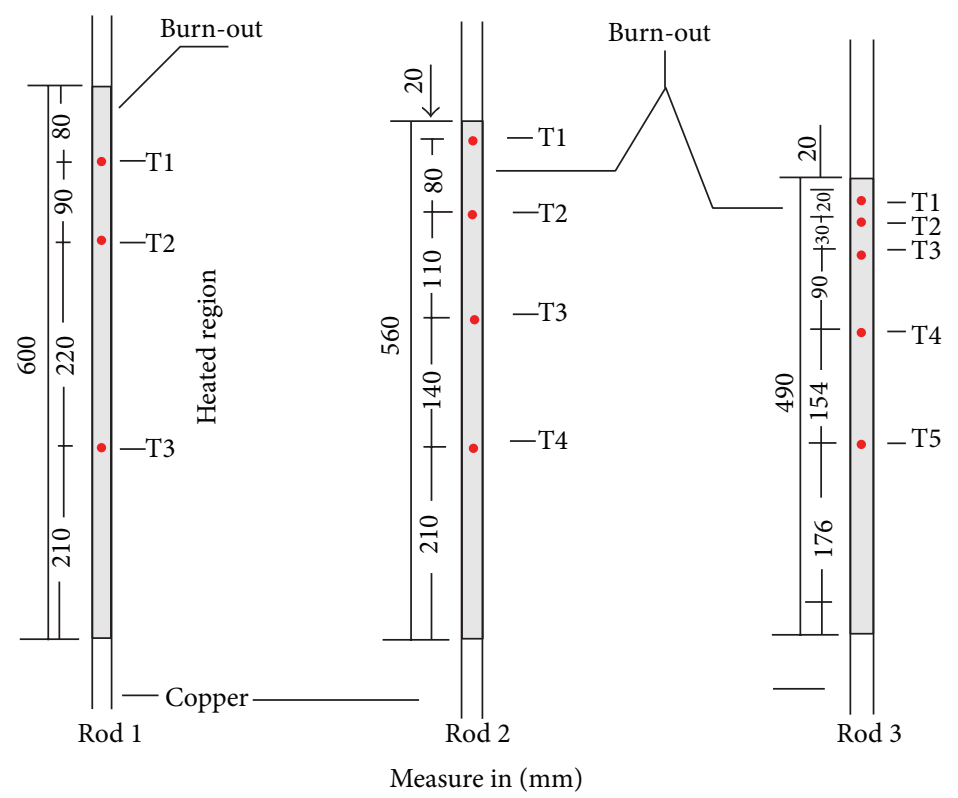

T1, T3, T5 Unshielded thermocouples

T2, T4 Shielded thermocouples

FIGURE 4: Simulators rods.

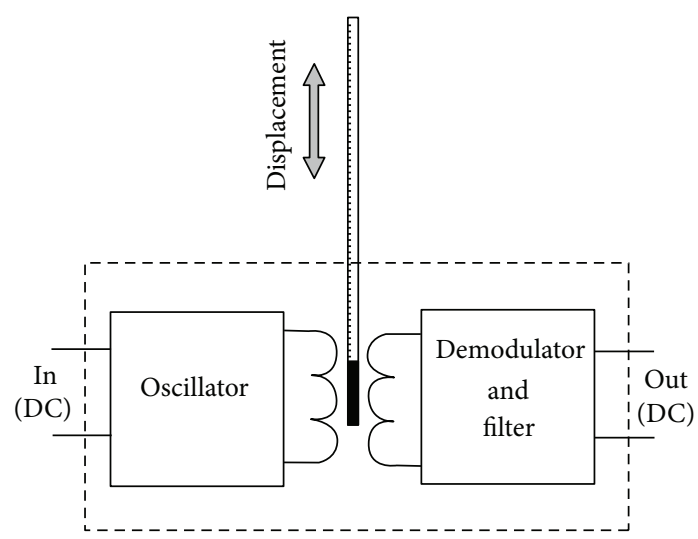

FIgURE 5: Simplified functional diagram.

temperature provided by the thermocouple T1. The different values of the maximum temperature are probably due to the detection delay of the critical flux by the thermocouple.

In the first test, carried out with a Rod 1 , just the transducer was able to detect the critical heat flux. The power was not turned off to see if the thermocouple would be able to detect the flow, and there was rupture of the rod.

When the rod was exchanged, it was observed that the rupture happened about $20 \mathrm{~mm}$ of the superior extremity. The closest thermocouple was located about $40 \mathrm{~mm}$ distant from this point. It was concluded that due to the distance, the thermocouple did not detect the burnout.

In Rod 2, the thermocouples were concentrated on the upper part where there is a great probability of occurrence of the critical flow. In all tests, the transducer detected the appearance of the critical flux, and the power supply was turned off. Test 2 was one of the few tests that the thermocouple could detect the burnout being detected $11 \mathrm{~s}$ after the transducer detection. Figure 6 shows the evolution of the wall temperature and the output signal of the transducer during Test 2.

In Test 4, after the detection of the critical flux by the transducer, purposely did not turn off the power, leaving the rod to burn. Again the thermocouple detects the occurrence of the burnout. When the rod was exchanged, it is observed that the rupture happened approximately about $15 \mathrm{~mm}$ of the upper end and $17 \mathrm{~mm}$ of the closest thermocouple.

In Rod 3, another thermocouple was increased concentrating them on the superior part. It took place ten tests with this rod, and in just only one of them (Test 14), one of the thermocouples detected the critical flux.

Figure 7 shows Test 14. The time delay between the detection using the displacement transducer and thermocouple T1 was $22 \mathrm{~s}$. Rupture of the fuel rod in this test has occurred.

4.2. Heating with a Torch Flame. An experience was realized where the abrupt increase of the temperature was provoked by flame of a torch from oxyacetylene welding equipment. This experiment was conducted to have an idea on the accuracy of detection by the displacement transducer and also to know the answer in the thermocouple detection as a function of burnout occurrence.

Rod 3 was removed from the test vase and fixed on the downdside in the vertical position. In this ways the upper end could dilate freely and act on the coil of the displacement transducer. The flame of the torch was set to the most possible punctual, and the rod was heated at some points at different 
TABLE 1: Experimental results.

\begin{tabular}{|c|c|c|c|c|c|c|c|}
\hline Test & Rod & $\begin{array}{c}\text { Power } \\
{[\mathrm{W}]}\end{array}$ & $\begin{array}{l}\text { Heat flux } \\
{\left[\mathrm{W} / \mathrm{cm}^{2}\right]}\end{array}$ & $\begin{array}{l}\text { Time } \\
{[s]}\end{array}$ & $\begin{array}{c}\text { Temperature } \\
\text { (maximum) } \\
{\left[{ }^{\circ} \mathrm{C}\right]}\end{array}$ & $\begin{array}{l}\text { Rod dilation } \\
\quad[\mathrm{mm}]\end{array}$ & $\begin{array}{c}\text { Thermocouple delay } \\
{[\mathrm{s}]}\end{array}$ \\
\hline \multirow{7}{*}{2} & \multirow{7}{*}{2} & 0 & 0.0 & 0 & 52 & 0.05 & \\
\hline & & 966 & 5.1 & 86 & 76 & 0.06 & \\
\hline & & 3093 & 16.4 & 131 & 92 & 0.07 & \\
\hline & & 4656 & 24.6 & 167 & 103 & 0.07 & \\
\hline & & 8286 & 43.8 & 215 & 103 & 0.08 & \\
\hline & & 10101 & $53.0^{*}$ & 242 & 103 & 0.70 & \\
\hline & & 0 & 0 & 253 & 250 & 0.20 & 11 \\
\hline \multirow{8}{*}{3} & \multirow{8}{*}{2} & 0 & 0.0 & 0 & 65 & & \\
\hline & & 1019 & 5.4 & 178 & 100 & & \\
\hline & & 4042 & 21.4 & 214 & 100 & & \\
\hline & & 6180 & 32.7 & 228 & 100 & & \\
\hline & & 7713 & 40.8 & 233 & 100 & & \\
\hline & & 9049 & 47.8 & 239 & 100 & & \\
\hline & & 10626 & $56.2^{*}$ & 257 & 100 & & \\
\hline & & 0 & 0.0 & 310 & 100 & & 54 \\
\hline \multirow{7}{*}{4} & \multirow{7}{*}{2} & 0.0 & 0 & 0 & 74 & & \\
\hline & & 9.0 & 36 & 36 & 76 & & \\
\hline & & 23.0 & 90 & 90 & 102 & & \\
\hline & & 33.2 & 122 & 122 & 102 & & \\
\hline & & 48.2 & 142 & 142 & 102 & & \\
\hline & & $57.0^{*}$ & 150 & 150 & 102 & & \\
\hline & & 0.0 & - & - & 102 & & Not detected \\
\hline \multirow{7}{*}{13} & \multirow{7}{*}{3} & 0 & 0.0 & 0 & 53 & & \\
\hline & & 1717 & 10.4 & 45 & 59 & & \\
\hline & & 3647 & 22.0 & 138 & 96 & & \\
\hline & & 6397 & 38.7 & 159 & 99 & & \\
\hline & & 9270 & 56.0 & 169 & 99 & & \\
\hline & & 13869 & $83.8^{*}$ & 184 & 100 & & \\
\hline & & 0 & 0.0 & - & 100 & & Not detected \\
\hline \multirow{6}{*}{14} & \multirow{6}{*}{3} & 0 & 0.0 & 0 & 20 & 0.4 & \\
\hline & & 4558 & 27.5 & 135 & 96 & 1.0 & \\
\hline & & 5622 & 34.0 & 173 & 107 & 0.8 & \\
\hline & & 12050 & 72.8 & 205 & 110 & 0.7 & \\
\hline & & 14440 & $87.3^{*}$ & 211 & 210 & 1.3 & \\
\hline & & 0 & 0.0 & 232 & 185 & 0.2 & 22 \\
\hline
\end{tabular}

${ }^{*}$ Departure from nucleate boiling.

times. The signals from the displacement transducer and thermocouple were monitored using the video monitor of the data acquisition system.

When the place became red, the flame was put out and it could be observed that the transducer immediately signaled the beginning of burnup. It was found that these indications are simultaneous, considering the means of observation (visual and video monitor). Moreover, the response of the thermocouple varied according to the heating location, showing that for distances greater than $50 \mathrm{~mm}$, the thermocouple hardly could detect the temperature increase.

Figure 8 shows the graphics that indicate the delay time in the thermocouple indication and its relationship with the answer of the transducer, in function of the distance of the red spot produced by the flame. The thermocouple was used without shielding, where the inertia is smaller. The graphic 


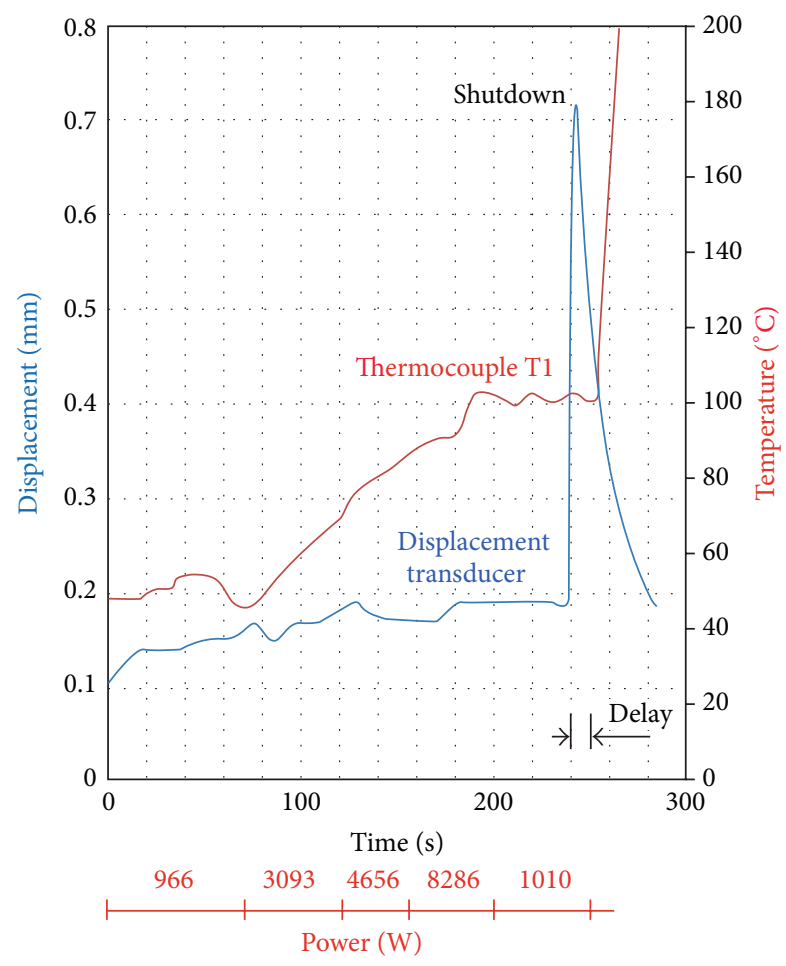

FIGURE 6: Evolution of the temperature and of the sign of the transducer during Test 2.

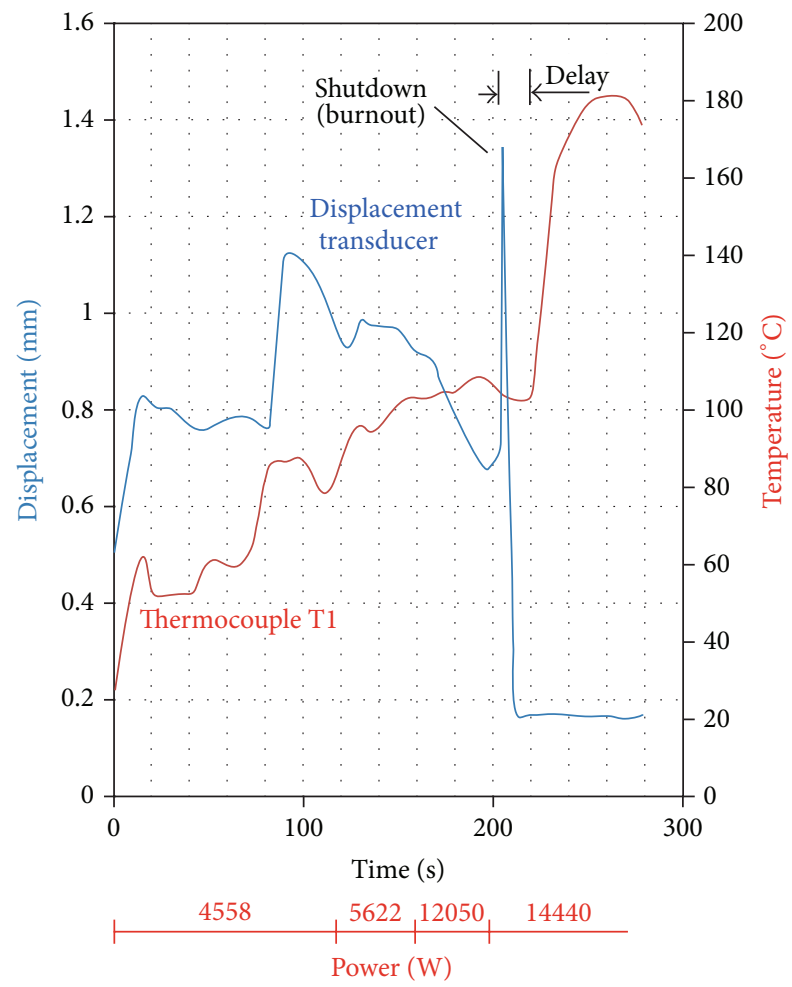

FIGURE 7: Evolution of the temperature and of the sign of the transducer during Test 14.

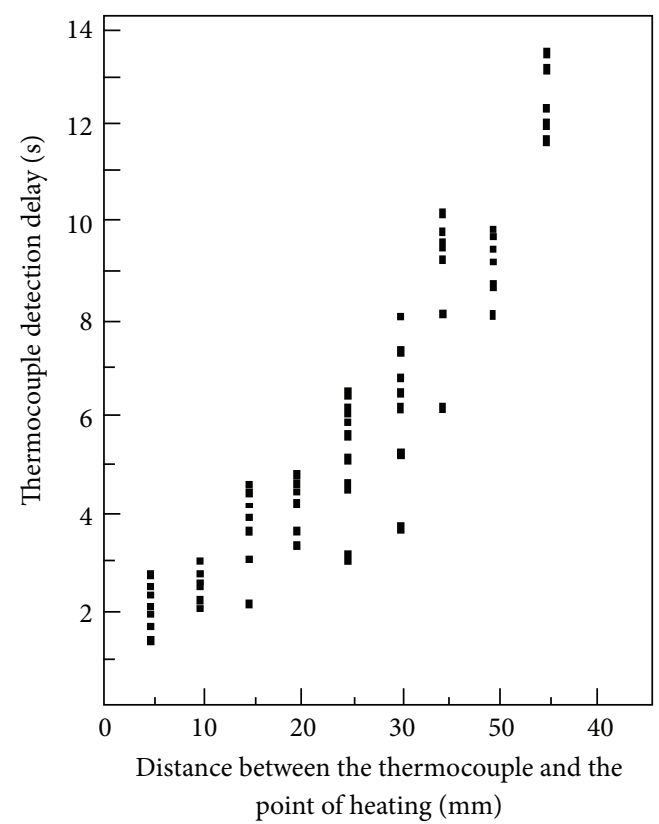

FIgURE 8: Time delay in the thermocouple signal with relationship with the transducers.

shows that there was a great dispersion in the time of answer of the thermocouple.

\section{Conclusions}

In outreactor heat transfer experiments, electrically heated rods often simulate fuel elements. In order to prevent the heating rod from being damaged by burnout, when the critical heat flux occurs, a safety system is provided which checks the axial thermal expansion of the rod. In case of a sudden temperature increase, the corresponding elongation causes a fast interruption of the electrical power supply.

The experiments showed that the use of the displacement transducer is the most efficient technique to detect the critical flux in simulators rods with direct heating in open pool. The dilatation method of CHF detection preserved the test section and allowed multiple tests to be conducted with a single test section. The experiments presented here indicate that this method is more effective than the one that uses thermocouples. In this process, unlike the thermocouples uses, the detection does not depend on the place where the critical heat flux happens. In spite of no having compared it with the method of Wheatstone bridge (change of the electric resistance), it can be affirmed that it is at least practical, because it does not need previous adjustments (balancing). The following experiment will measure the critical heat flux and make a comparison with the theoretical values.

\section{Acknowledgments}

The following Brazilian institutions support this research project: Nuclear Technology Development Centre (CDTN), Brazilian Nuclear Energy Commission (CNEN), Research Support Foundation of the State of Minas Gerais (FAPEMIG), 
and Brazilian Council for Scientific and Technological Development $(\mathrm{CNPq})$.

\section{References}

[1] D. G. Reddy, C. F. Fighetti, and M. Merilo, "Prediction of critical beat flux in PWR fuel assemblies with non-uniform axial heat flux distribution," in Proceedings of the 7th International Heat Transfer Conference, vol. 4, pp. 333-338, Hemisphere Publishing, München, Germany, 1982.

[2] F. J. Arias, "Film boiling in magnetic field in liquid metals with particular reference to fusion reactor project," Journal of Fusion Energy, vol. 29, no. 2, pp. 130-133, 2010.

[3] D. D. Hall and I. Mudawar, "Critical heat flux (CHF) for water flow in tubes-I: compilation and assessment of world CHF data," International Journal of Heat and Mass Transfer, vol. 43, no. 14, pp. 2573-2604, 2000.

[4] M. Avery, J. J. Yang, M. Anderson, and M. Corradini, "Critical heat flux in TRIGA-fueled reactors cooled by natural convection," Nuclear Science and Engineering, vol. 172, pp. 249-258, 2012.

[5] A. Bounakov, "Verification of calculation technique of critical heat flux In RELAP5/MOD3. 2 code applied to the MIR research reactor on experimental data obtained for the annulus at average water pressures," Budapest, Hungary, 1998.

[6] M. Decreton, "Boiling crisis in restricted geometries with the near-by cooled wall," in Proceedings of the 7th International Heat Transfer Conference, vol. 4, pp. 107-lll, Hemisphere Publishing, Müchen, Germany, 1982.

[7] Hewlett-Packard Company, "Displacement transducers series 7DCDT \& 24DCDT," Technical Data, Hewlett-Packard Company, Waltham, Mass, USA, 1977. 


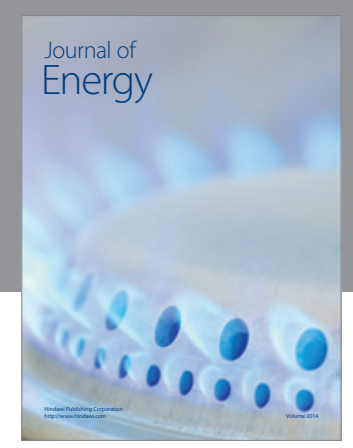

Journal of

Industrial Engineering
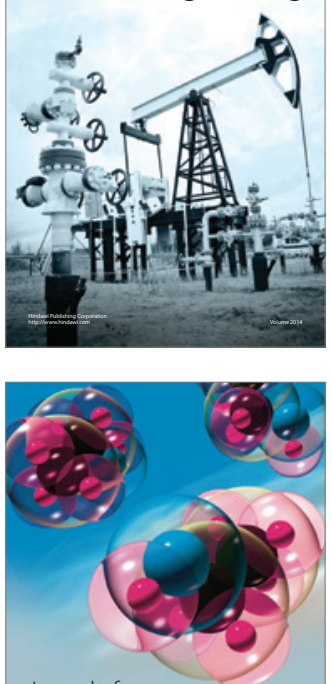

Fuels
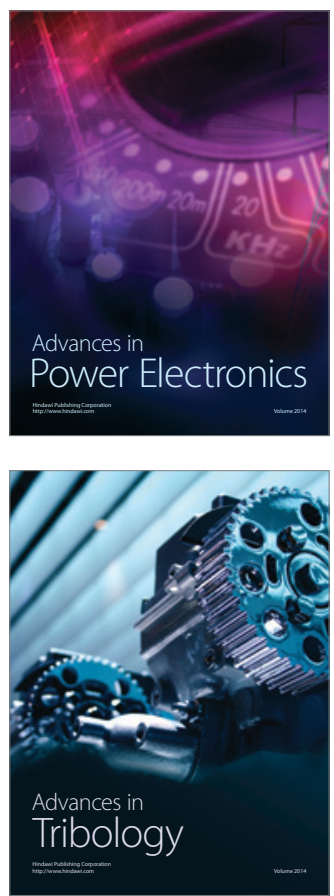

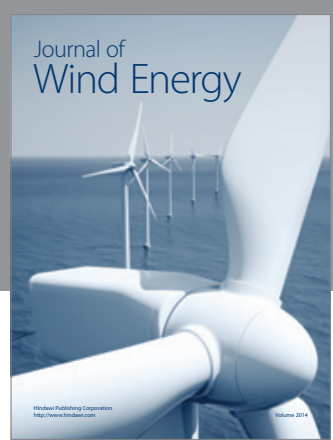

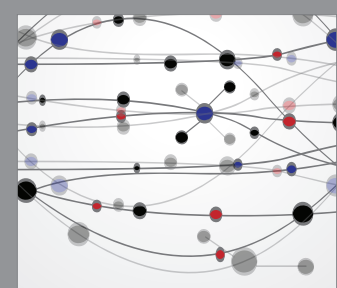

The Scientific World Journal

Submit your manuscripts at http://www.hindawi.com

Journal of

Structures
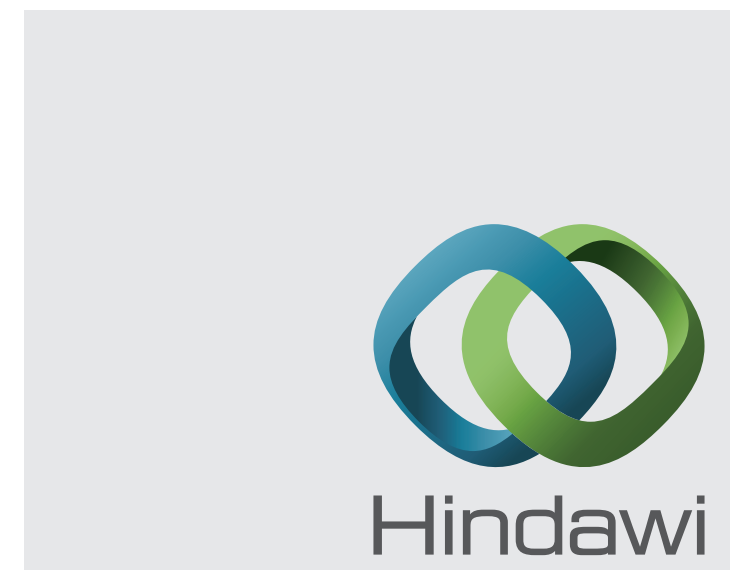

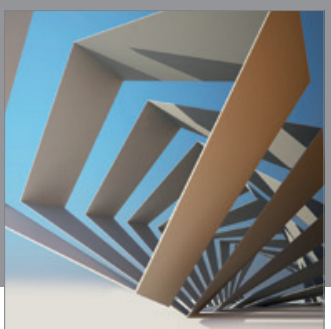

Rotating

Machinery
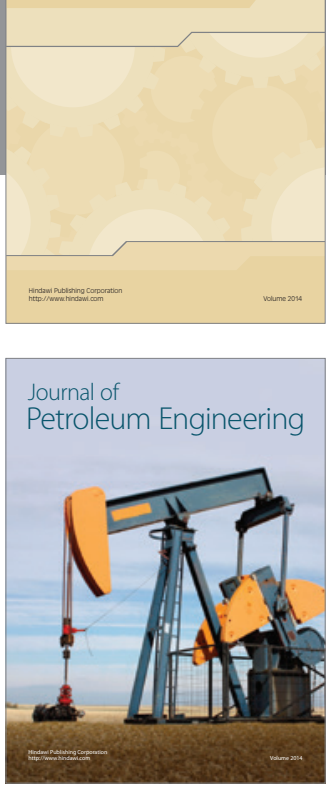

Journal of

Solar Energy
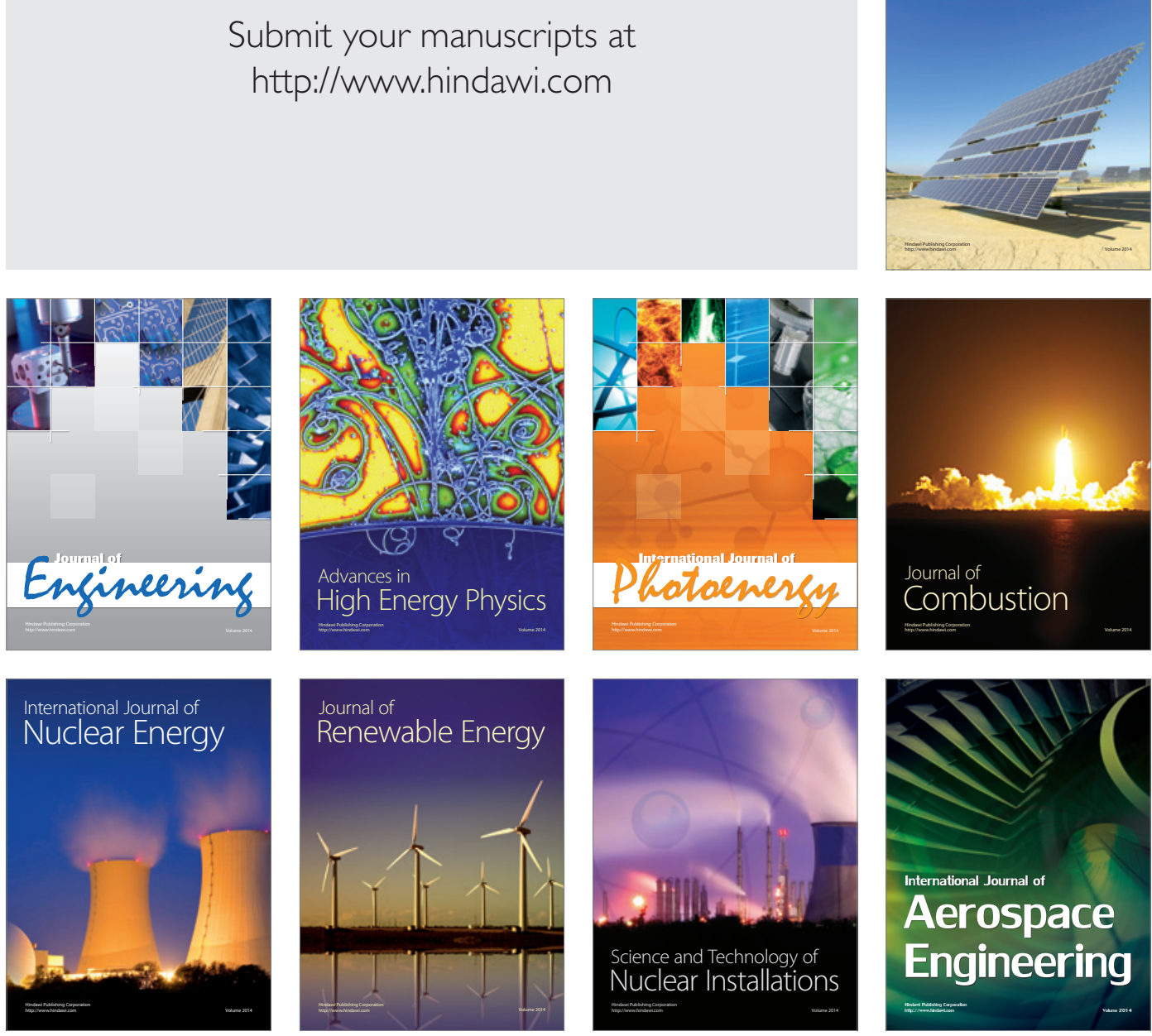